\title{
Education for Moral Integrity
}

\section{ALBERT W. MUSSCHENGA}

This paper focuses on coherence and consistency as elements of moral integrity, arguing that several kinds of - mostly second-order - virtues contribute to establishing coherence and consistency in a person's judgements and behaviour. The virtues relevant for integrity always accompany other, substantive virtues, and their associated values, principles and rules. In moral education we teach children all kinds of substantive virtues with integrity as our goal. Nevertheless, many adults do not attain moral integrity, although they are clearly not immoral. What precisely are they lacking? Education for moral integrity should focus on strengthening motivational self-sufficiency, furthering critical and imaginative thinking and promoting moral unity.

\section{INTRODUCTION}

The term 'integrity' is widely used in praising, evaluating, remembering and recommending people. Integrity is both a desired and a desirable characteristic. In spite of the currency of the term, very little has been written about what it takes to educate persons for integrity. In this article I want to contribute to filling this gap.

In the first part of the article I analyse the meaning and use of the term 'integrity'. The various concepts of integrity we meet in ordinary language can be categorised along two axes: formal-material and localglobal. This categorisation results in three concepts of integrity: the formal concept of personal integrity, and the material concepts of local and moral integrity. I focus mainly on moral integrity.

These concepts share the same logic or rationale: we are interested in the reliability of people and the predictability of their behaviour, in general or in particular roles. The interest in integrity leads us to investigate the coherence and consistency of the sayings and doings of those we have to deal with. However, how do we determine whether someone's behaviour and judgements are not sufficiently consistent and coherent? How much coherence and consistency must a person exhibit for integrity to be attributed to him? I discuss the relation between integrity and coherence and consistency in the second part of this article. 
In the third part I turn to the issue of education for integrity. I argue that several kinds of - mostly second-order-virtues contribute to establishing some degree of coherence and consistency in a person's judgements and behaviour. Being second-order virtues, the virtues relevant for integrity always accompany other, substantive virtues - and the values, principles and rules associated with those virtues. In the case of local and moral integrity these are the virtues that make up excellence of conduct in a specific context or moral excellence in general. In the case of personal integrity the relevant virtues are those required for fulfilling the commitments a person has incurred voluntarily. In view of the fact that the virtues relevant for integrity are always related to substantive virtues, it seems obvious to assume that one cannot separate education for moral integrity from teaching substantive virtues. This is indeed true for the moral education of children. We teach children all kinds of substantive virtues in such a way that they might attain some degree of integrity. But in spite of the efforts of parents and schools, many adults do not meet our standards of moral integrity, although they are clearly not immoral. What precisely are they lacking? I argue that the focus in educating for moral integrity should be on strengthening motivational self-sufficiency, furthering critical and imaginative thinking and promoting moral unity.

\section{CONCEPTS OF INTEGRITY}

Many Americans who voted for John McCain to become the Republican presidential candidate did not primarily support him for his rather conservative ideas. They especially favoured him because he was what in their view Bill Clinton definitely was not-a man of integrity. Gert Schutte, a Dutch politician, is regarded by many as 'the conscience of Dutch politics'. He belongs to one of the small conservative Christian political parties that condemn homosexual behaviour and are not much in favour of equality between the sexes. These views are strongly rejected by the greater part of Dutch society. But, although many do not share Schutte's moral and political convictions, that does not keep them from calling him a person of integrity. What unites those we regard as persons of integrity is that they stick to their promises, act according to the principles they have subscribed to or are expected to act upon in the offices and roles they fulfil, and are loyal to their commitments. There is, in other words, consistency between what they say, profess and promise, and what they actually do, not only under favourable but also under unfavourable circumstances. A person of integrity is able to resist external pressure as well as temptations. He will never abuse the power, privileges and opportunities that his role provides. He shows what I call external consistency.

External consistency between saying and doing is the first important aspect of integrity. Integrity often refers not only to such external 
consistency but also to the internal coherence and consistency between his beliefs, values and conduct. ${ }^{1}$ Having integrity is often described as being 'of one piece' or being 'a whole person'. However it is not clear from ordinary language to what extent someone's beliefs and values should display consistency and coherence for him to be called a person of integrity. Many persons who are undoubtedly seen as persons of integrity are not, or have not always been, completely consistent in all their behaviour. I assume that hardly anybody would deny that Martin Luther King, the relentless and inspiring campaigner for equal rights, was an honest, dedicated and loyal person, a person of integrity. This in spite of the fact that he was known to have extramarital affairs. But Bill Clinton, a president dedicated to his office, also not without charisma, acquired the reputation of not being a person of integrity because of his sexual affair with Monica Lewinski and his lying about it. There is clearly disagreement about whether integrity requires internal coherence and consistency between the beliefs and values of a person in all roles and domains of his life, or between only those in a particular role or context; about whether integrity is a global or a local concept-whether or not it is a precondition for calling, say, a politician a person of integrity that he is virtuous in all his social roles and in all domains of his life.

Consistency and coherence are formal concepts. They refer to the relations between someone's beliefs and conduct. In some cases judgements concerning integrity only evaluate the quality of these relations, abstracting from the substance of a person's beliefs, principles and commitments. In other cases in evaluating integrity one starts from values, principles and rules that are valid in the agent's own community and examines how the subject deals with them and how they are expressed in his behaviour. We are not inclined to call a politician who chooses his own rules and standards a person of integrity even if there is internal coherence and consistency between his values and beliefs, and external coherence between what he says and does. Thus, the basis for judging the integrity of, say, a prime minister, is not his self-chosen principles and values. Like any other person who fulfils a political or public role, a prime minister is expected to act in accordance with the social rules, values and standards that are constitutive for that specific role. A politician needs to play the game according to its constitutive, social rules, and not according to his own, idiosyncratic rules. Notwithstanding that, we do from time to time praise, for example, socially 'deviant' revolutionaries for their integrity because they live up to their own principles and are willing to go to prison or even die for them. Thus, we need to make a second distinction, in addition to the above-mentioned distinction between the local and global concepts of integrity - namely, between formal and material concepts of integrity. Taking these two pairs of distinctions together-local versus global and formal versus material - we get, at least in theory, four different concepts of integrity. This is made visible in the matrix below (Figure $1)$ : 


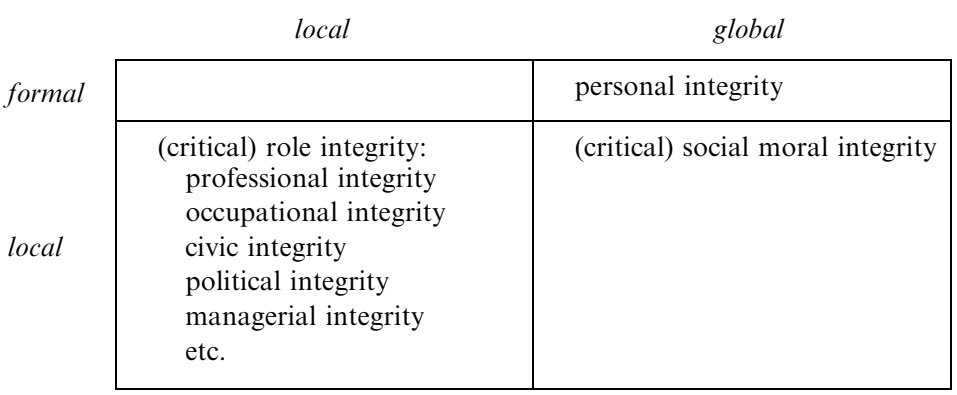

Figure 1. Concepts of integrity

The first cell of the matrix is empty. The local and formal concept of integrity does not appear in ordinary language. It is only a theoretical possibility. The material local concept is the one most frequently used. This is not surprising. People in modern, highly differentiated societies are dependent on all kinds of often anonymous officials, experts, producers and retailers for getting goods, benefits, services, treatments and so on. Therefore they have, especially when the relations are asymmetrical, an interest in the trustworthiness and reliability of persons acting in such roles or capacities. The formal and global concept of personal integrity is, I think, found more in academic literature than in ordinary language. The concept of moral integrity is the most conventional and perhaps central one.

\section{THE DEFINITION OF MORAL INTEGRITY}

When we praise someone for having personal integrity we usually mean that there is internal coherence and consistency between his various convictions, and external consistency between what he professes and what he actually does. In this use integrity is a formal and global concept. By 'formal' I mean that we only evaluate the quality of the relations between someone's convictions and behaviour, thereby abstracting from the substance of his projects and convictions-we assume that they are sound; ${ }^{2}$ by 'global' I mean that we take the whole range of his projects, convictions and actions into account, and not only those in a particular role. Persons possessing personal integrity have, in Howard Kamler's terminology, an identificatory self and act consistently according to their identificatory valuations. Identifying with something implies for him positing total value in it. The positing of identificatory valuations is an autonomous act (Kamler, 2001). In some accounts, personal integrity seems to boil down to being psychologically integrated or having unified agency. In my view someone with personal integrity not only shows coherence and consistency in his convictions and coherence, he also has a distinctive character, in which his identificatory valuations reflect his deepest convictions. A man of personal 
integrity is true to himself, has authenticity. A more extensive elaboration of the relation between unified agency and personal integrity is beyond the scope of this article (see Musschenga, 2001).

What then is moral integrity? We value integrity because it is connected with the trustworthiness and reliability of people and the predictability of their behaviour. While our interest in personal integrity is mainly agent-centred, our interest in moral integrity seems to be more behaviour-centred. That is, we want to know whether they have integrity because we have an interest in their behaviour, and not the other way around. We want to be sure that they will do what they are morally expected to do. In this view moral integrity is intimately linked with the social side of morality and of obvious relevance to education for citizenship. $^{3}$

In judging a person's moral integrity one starts from the substantive virtues, principles and values that are seen as essential for the diverse social roles people normally fulfil in a society, and examines how these are manifested in his conduct. The behaviour and judgements of people having moral integrity show external consistency and internal consistency and coherence. Moral integrity shares this feature with personal integrity. People having personal integrity differ from those having moral integrity as to the nature of their self's core. The selves of persons having moral integrity are constituted by socially-shared moral identityconferring commitments.

The term 'moral' in my concept of moral integrity is conceived 'narrowly'. It presupposes a particular definition of 'moral' and 'morality'. Especially since John Mackie published his Ethics, moral philosophers have disagreed about whether to conceive morality 'broadly' or 'narrowly'. According to Mackie, morality in the broad sense is a general, all-inclusive theory of conduct: the morality to which someone subscribed would be whatever body of principles he allowed ultimately to guide or determine his choices of action. In the narrow sense morality is a particular social system of constraints on conduct whose central task is to protect the interests of other persons than the agent and which presents itself to an agent in the form of checks on his natural or spontaneous tendencies to act (Mackie 1977, p. 106). ${ }^{4}$

We do not call someone who leads a life of crime a person lacking moral integrity. He or she is simply immoral, without further qualification. A person lacking moral integrity is not immoral, he is imperfectly moral. How do we determine that? The obvious answer is: by looking at the consistency and coherence of his behaviour and judgements. This answer is less clear than it looks. How do we determine whether someone's moral behaviour and judgements are not sufficiently consistent and coherent? Whose point of view should we take in evaluating someone's integrity: that of the subject or that of a third person? In the next sections I explore the relations between observations of incoherence and inconsistency and unified agency. I argue that in many cases, observations of incoherence and inconsistency can be reconciled with having unified agency. 


\section{INTEGRITY AND THE CONTEXT-DEPENDENCE OF MORALITY}

Professional ethics offers many examples of situations in which a professional acts contrary to common public morality. Sometimes, in giving treatment, doctors cause pain to their patients. Businessmen destroy their competitors. Lawyers serve the cause of their clients, and not the cause of justice. Psychiatrists, social workers, pastors and priests sometimes obstruct the legal process by appealing to their duty of confidentiality in withholding information. Journalists do the same by refusing to reveal their sources. In particular cases persons may succeed in taking away doubts about incoherence and inconsistency between their private and professional behaviour by referring to the special nature of professional privileges and obligations.

\section{INTEGRITY AND FRAGMENTATION (1)}

We assume that when a person shows a character trait in one situation or context, this trait will also determine his behaviour in other situations or contexts. If this does not happen, we easily conclude that he lacks integrity. Owen Flanagan calls this assumption 'trait globality'. Referring to a number of psychological studies he argues in his Varieties of Moral Personality that trait globality does not exist (Flanagan, 1991, ch. 13). ${ }^{5}$

Some time ago I heard about a man working at the Dutch Ministry of Defence, who in his free time was active in a gang of hooligans. Perhaps he did not have a very elevated position at the Ministry, but as far as I know he did his job well. He must therefore - at least in his conducthave shown virtues and dispositions that made him suitable for the job. I read some books about hooligans which gave me some insight into their motives. I still, however, wondered how it was possible that a man working at this ministry could at the same time be a hooligan. I could not imagine that a psychologically normal person would be able to integrate such divergent patterns of behaviour.

Suppose I meet this man and ask him how he can reconcile his being a hooligan with the kinds of virtues and dispositions he needs to be a good civil servant. He tells me the following story. He is very concerned about the spread of violence in society and about its gradual acceptance as a normal phenomenon. He has come to the conclusion that a concentrated outburst of severe violence would cause such unrest in society that the authorities would be forced to take severe measures. That is why he has joined the gang: to be able to encourage the gang to organise such an event.

This person attempts to weaken my suspicion that he is behaving inconsistently by offering a narrative explanation of his behaviour. In his view there is narrative coherence between his behaviour in the contexts of his work and his free time. ${ }^{6}$ Provided that I have no reason to doubt the man's sincerity, the only thing I seem able to do to check his integrity is to evaluate the coherence of his story. If this civil servant is 
able to convince me that his activities as a hooligan fit into his selfnarrative, I seem to have no ground to doubt his unified agency.

\section{INTEGRITY AND FRAGMENTATION (2)}

Imagine your daughter comes home with a man she introduces as the one she is going to marry. After some enquiries you discover he is a tough businessman with a reputation of not shrinking from whatever means to destroy his competitors. I am sure this knowledge will cause you to doubt whether this man will be the caring and loyal husband you wish for your daughter. However, your observations of his behaviour do not provide evidence for your suspicions. He is fond of your daughter and surrounds her with all the love and care you could wish. You now tend to think that he is either not as ruthless as a businessman as people say or he is not sincere in his behaviour towards your daughter or he is slightly schizophrenic. You decide to talk to him about your worries. He is very surprised by what you say. He does not see why he could not be at the same time a caring and attentive husband and a tough businessman. He has no problem in combining these patterns of behaviour.

Psychological researches give evidence of a strongly compartmentalised picture of personality traits. A person can be honest and at the same time cruel, just and cowardly, and so on (Flanagan, 1991, p. 287 ff.). Such a person need not experience any incoherence in her behaviour in the different contexts. This observation conflicts with what Flanagan calls folk psychology's belief in 'evaluative consistency'; and also with the philosophical doctrine of the unity of virtues that tells us that someone cannot be said truly to possess a virtue when he does not have all the other virtues. A person who behaves as a caring and loyal husband cannot be said to posses these virtues if he turns out to be a ruthless businessman who lets nothing stand in his way. ${ }^{7}$

\section{INTEGRITY AND INTERNAL CONFLICTS}

Second or third-generation members of ethnic-cultural groups in The Netherlands are often said to 'live between two cultures'. They experience conflicts and tensions between the norms and values of Dutch culture and those of their own group. This is especially the case with children whose parents' culture differs substantially from Dutch culture, such as Turkish and especially Moroccan children. The experience of conflict and tension is probably more intense among girls than among boys because of the great differences in ideas about the equality of the sexes between traditional Turkish and Moroccan culture and mainstream Dutch culture. It often happens that daughters leave their parents because they are not granted the freedom and independence that is enjoyed by indigenous Dutch girls. Since familial bonds are of great importance to the Turks and Moroccans, breaking contact with the family or being expelled from the family constitutes a severe emotional loss to these girls. They value and need their family as well as 
their independence. That is why many girls try to avoid a situation in which a breach with their family becomes unavoidable. Therefore they choose to submit at home to the traditional authority of their father, while striving for independence in the world outside.

If someone can only establish consistency at high cost, should we blame her if she decides to live with inconsistency of this kind? The Moroccan girl in our example above decides not to resolve the conflict between the values of autonomy and belonging. By doing so, she shows integrity. Only from the point of view of an observer is the girl inconsistent in her conduct. Maybe she is able to convince us that the conflict underlying the inconsistency continues not because she is unable to make up her mind, but because she has decided wholeheartedly not to resolve the conflict. The persistence of internal conflicts resulting in observable behavioural incoherence and inconsistency may give rise to the suspicion that someone lacks integrity, but it does not constitute a proof.

\section{THE CRITICAL DIMENSIONS OF MORAL INTEGRITY}

Social morality refers to the whole set of moral values and principles for guiding actions impinging on the welfare and interests of others that is accepted as authoritative by a particular community. Members of that community can comply with these values and principles without personally subscribing to or endorsing them. Moral integrity does not refer to slavish and unreflective following of social rules and conventions. Moral integrity presupposes that a person has identified himself with social moral values and principles. A person's social morality will usually coincide largely with that of his community. But it may also relate critically to that community's positive morality. A person of moral integrity is not only loyal to the values, principles and obligations of his community's positive morality. He has internalised, appropriated them, which implies that he knows their rationale, knows how to interpret them and how to criticise existing, conventional applications. A person of moral integrity cannot just conform to the prevailing morality. His interpretations and application of his community's moral values, principles and ideals may therefore deviate from what is usual in his community. This may raise the suspicion that he lacks coherence and consistency.

\section{MORAL INTEGRITY, COHERENCE AND CONSISTENCY}

What has become clear by now is that, where incoherencies and inconsistencies in beliefs and conduct, or between conduct in different but relevantly similar situations, are apparent, we should not be too quick to conclude that this constitutes lack of integrity. It may of course happen that a person concedes to his critical observer that he is not always consistent. This confession will probably lead to a discussion about the causes of the deficiency in integrity. One obvious 
cause is weakness of will; another possibility is that the person lacks sufficient phronessis - the capacity to determine when the virtues, principles, values and rules he endorses are relevant in particular cases - and this is an intellectual virtue. Such a confession seems to be the exception rather than the rule. I assume that in most cases a person who is thus criticised will react by arguing that his behaviour has been misunderstood.

Take the example of the Dutch civil servant. He may counter any objections of inconsistency by saying that his conduct has been misinterpreted. From his own point of view it is consistent. When the critic is interested in moral integrity and not just in unified agency or personal integrity, he will respond that narrative coherence is not decisive in this case. He is willing to accept that the person seriously strives for coherence and consistency. He argues, however, that narrative coherence may be sufficient for unified agency and personal integrity, but not for moral integrity. Judgements about moral integrity are not based upon the person's own convictions, but upon his society's positive social morality.

I think that the picture is a little more complicated than this critic suggests when stressing that judgements about moral integrity are based upon the society's positive social morality. Although a person's own point of view has no primacy in judging his moral integrity, we cannot completely discard the reasons he provides for his behaviour. Of course, when observations of inconsistency raise doubts about someone's moral integrity, we are not inclined to be satisfied with a story in which that person tries to convince us that the alleged inconsistencies between belief and action, and among actions in various contexts, are compatible with his self-narrative. What we want to know in cases like that of the civil servant is whether the person is seriously striving for coherence and consistency and, if so, whether he is able to justify the alleged inconsistencies as flowing from a plausible interpretation and weighing not of his purely personal principles and values but of those of his community. Social morality is not a matter of sets of virtues and principles with crystal clear criteria of application and interpretation. In almost every case there are various legitimate interpretations of the relevant virtues, principles and values. This kind of public justification should be distinguished from purely narrative, first-person explanations. In public justification it is 'the public' - that is, a third party - that decides whether or not a justification is acceptable. However, a person might argue that his 'public' is not the local community, but a wider one, for example the global community.

The example of the Moroccan girl shows that the quest for coherence and consistency can also be driven too far. Of course, there is always the possibility that someone simply prefers to live by double standards because she lacks the will-power to make up her mind or because she wants to please everybody. However, the double loyalty to two cultures might also be constitutive of this girl's identity. She has decided not to choose between diverse, incompatible and incommensurable goods. She 
prefers to live with the tragedy of a certain disunity. This is a different case in which we should not force her to more coherence.

What lesson should we draw for moral integrity from our discussion about evaluative consistency? The insight that the idea of the unity of virtues is, at least as an empirical thesis, wrong should perhaps prevent us from accusing someone who is just but not courageous of lacking personal integrity. Moral integrity, however, is much more than sheer coherence and consistency. It concerns what it takes to be a whole, a completely moral person. There is no reason why we should be satisfied that a person who is evidently just but lacks other important virtues has personal integrity - although it is realistic to assume that the idea of the whole moral person will never be more than a kind of regulative ideal.

\section{VIRTUES OF INTEGRITY}

The logic or rationale of all talk of integrity is that we have an interest in the reliability of people and the predictability of their behaviour, in general or in particular roles. We have identified two aspects that the three concepts of integrity have in common: internal coherence/ consistency and external coherence. Integrity thus refers to particular qualities of people's judgements as well as to their behaviour. If we want to influence people's integrity by educating them, we need to know more precisely what determines a person's integrity. Are there differences in character between those who do and those do not exhibit integrity? What kinds of capacities and dispositions do persons of integrity have? What are the differences in the capacities and dispositions required for having personal and for having moral integrity? I will just enumerate dispositions and virtues that I think are relevant for establishing consistency and coherence. I distinguish between virtues of form, virtues of unified agency, intellectual virtues, volitional virtues and virtues of substance. Virtues of form are, for example, honesty, openness, sincerity, loyalty and dedication. They refer to the quality of someone's communication about his convictions and behaviour, and to the quality of his commitment to a role, practice or set of practices. Virtues of unified agency are harmony, constancy, unity and permanency. They are of central importance to a person's reliability. Intellectual virtues are necessary for interpreting principles and rules in concrete situations; for determining the middle (to meson) between two extremes. Volitional virtues are, for example, self-control, perseverance and steadfastness. They are relevant for withstanding external pressures and internal temptations to act in a way contrary to normative expectations, values and standards.

Apart from the intellectual ones, these are second-order virtues. Second-order virtues inform us about how a person of integrity communicates, reasons and acts. Virtues of substance refer to what a person of integrity is expected to do-to the substantive values and principles that are constitutive of a particular role or to the values and principles that constitute moral life as a whole. To give an example: a 
judge who shows all the above-mentioned second-order virtues but is not just and impartial cannot be said to have moral integrity.

Since persons who have gone through a normal moral development will all possess to some degree these second-order virtues, the intellectual virtues and the moral virtues of their community, it is still not clear what the distinctive features of persons of moral integrity are. In my opinion the difference between average moral persons and persons of moral integrity is a difference in degree. Persons of moral integrity score higher on critical and imaginative thinking, motivational self-sufficiency and moral unity. Thus, education to moral integrity should concentrate on further developing these characteristics. In the following sections I elaborate these characteristics. In my accounts of motivational selfsufficiency and critical and imaginative thinking I draw on what I said above about situationism. The section on moral unity elaborates my argument on trait globality and the unity of the virtues.

\section{CRITICAL IMAGINATIVE THINKING}

Situationist psychology draws attention to the context-specificity of traits while common-sense belief is to the effect that traits have causal efficacy in a wide range of situations. Let us assume that the empirical findings of situationist psychology are convincing. The question is then what lesson should be drawn for ethics. An important characteristic of ethics and ethical theorising is the drive to more consistency, to continuously examining whether differences in attitudes and actions between situations can be justified by referring to morally relevant differences in the facts of the situations. I interpret the call for integrity as summoning us not only to do the same in exactly similar situations but to base our actions on a clear insight into the morally relevant differences and similarities between old and new situations. A person of moral integrity is not just someone who shows coherence in his virtuous behaviour. He is, for example, just when it is appropriate to be just, not only in situations in which he is accustomed to being just. He is aware of the dangers of unjustified selectivity in moral behaviour, of his own and his community's biases and prejudices. This requires no special capacities but the usual ones of role-taking, universalisation, fine-tuning and empathic imagination, which are covered by the intellectual virtues such as phronēsis.

I argued before that persons of moral integrity do not just conform to their society's positive morality but relate critically to it. Thus, education for moral integrity differs importantly from mere moral habituation. Its aim is to bring it about that people come to regard moral values, principles and obligations, not as an alien constraining power, but as constitutive for their identity. As Kamler remarks, the positing of identificatory valuations is an autonomous act. But not every set of identificatory valuations is also a moral one. Education for moral integrity implies that people learn to understand the social character of morality. Morality regulates the social interactions between people and 
must therefore be acceptable to all concerned. A person's social morality cannot be authentic in the sense that he regards himself to be the inventor, the sole legislator of that morality. Social morality, however, requires dialogue and debate. In moral education there is an inevitable and everlasting tension between the demands of personal and of moral integrity.

\section{MOTIVATIONAL SELF-SUFFICIENCY}

The greater part of our moral life is regulated by the normative expectations of other people, derived from shared values, principles and rules. Our motivations to act morally are fuelled by the good examples of significant others, personal convictions, the approval and disapproval of others and so on. These motivations are usually strong enough to resist normal pressures and normal temptations. Of utmost importance for the strength of these motivations is whether the social environment does or does not reinforce them. Thus, situational and contextual factors determine to a great extent whether someone acts in a particular case on the principles he endorses and reflects in his behaviour the virtues he is known to have.

Much of the debate about moral integrity concerns situations in which people know what the right thing to do is but give in to threats or cannot withstand the temptations of money and other benefits. In such situations social support is too weak. Social support of morally right conduct is completely absent when practices such as fraud and bribery are widespread. Resistance against those practices begins with people who not only are convinced that these are wrong and detrimental to society but also have a strong internal motivation and are thus not completely dependent on the social support of others. One of the aims of education for integrity is to increase the motivational self-sufficiency ${ }^{8}$ of moral persons; to make their motivations for moral action less dependent on situational and contextual factors, on the sustaining social contributions of others.

This motivational self-sufficiency of moral persons depends, as August Blasi has shown, on the degree of centrality that what he calls 'moral concerns' (values, principles, virtues) have in a person's identity. Morality and identity/self-concept are according to him separate psychological systems which only slowly, and sometimes imperfectly, come together and become integrated. An important point he notes is that moral concerns do not seem to require a strong identity integration in order to be effective in someone's life. The difference between average moral persons and persons of moral integrity is that the latter have shaped their identities around moral concerns. Morality has become constitutive of their identity (Blasi, 1995). Persons have many commitments, only some of which are identity-constitutive. The average moral person does endorse moral values and does have moral commitments, but these commitments are not central to his identity. 


\section{MORAL UNITY}

A good judge has shaped his identity around the principle of impartial justice. He might show professional integrity and even personal integrity, although he lacks other moral virtues. I said before that the empirical psychological findings do not force us to be satisfied when a person who is evidently just lacks other important virtues. This does not mean that I embrace the classical doctrine of the unity of virtues. The doctrine wrongly presupposes that morality is a seamless web. Isaiah Berlin and others have, for me convincingly, shown that morality encompasses a plurality of diverse, sometimes conflicting, and partly incommensurable principles, virtues and values. It is humanly impossible that one and the same person unites in himself all virtues. Contrary to what the doctrine of the unity of the virtues suggests, there is not just one image of a completely moral person, there are more. Mother Teresa and Nelson Mandela are both persons of moral integrity, although they are completely different moral personalities.

The truth of the doctrine of the unity of virtues is that a person can only really know when to be just and when not where the virtue of justice is held in place by other virtues such as compassion and benevolence. ${ }^{9}$ One of the aims in educating for moral integrity is to stimulate the development of what I would call 'moral completeness'. What empirical research does show is that the education of the various virtues requires very different approaches. An elaboration of what such approaches might involve is beyond the scope of this paper.

Besides the phenomenon of the partly, incompletely moral person, I want to draw attention to another phenomenon which in my opinion is even more relevant to reflect upon when discussing moral unity: that of the divided moral personality. ${ }^{10}$ That is the person who acts morally in the diverse roles and domains of his life but lacks an overarching, integrating morality. Such a person either has consciously split himself up into different 'selves' or has not acquired or developed a general, context-transcending morality.

This phenomenon of the divided moral personality is described by Alasdair MacIntyre in a recent article (MacIntyre, 1999). What struck me in his analysis was his statement that this division of the moral self is not the logical outcome of the processes of division and differentiation that pervade modern society, but the result of decisions people take. The splitting up of moral personality is in MacIntyre's view an understandable, but reprehensible reaction to the nature of social life in a compartmentalised social order. It is a reaction for which people bear responsibility. I agree with MacIntyre that people seem to have a 'natural' tendency to connect the different parts and roles of their life in a self-narrative. The fact that it is quite difficult to integrate all the roles and parts of one's life might explain why some people do not even try to do so but instead are inclined to suppress that very tendency. It is difficult to distinguish cases in which people think it justified to act 
differently in various social roles from those in which people act differently without asking themselves whether this can be justified. An internally differentiated moral personality need not be a divided personality. I am not sure whether MacIntyre wants to make that distinction.

Really divided personalities adjust their behaviour in specific roles and contexts to what they know is morally expected in these roles and contexts. They never transcend the level of a purely external orientation to the expectations of others. Their diverse moral concerns and their identity are not integrated. Therefore, they will not be able skilfully to interpret and to apply the relevant moral values, principles and rules in new situations. Only those who have reflectively appropriated these concepts are able to do that. Anyone who reflectively appropriates values, principles and rules will be driven, in interpreting these concepts, to surpass the limits of a role or context. If I am right, a really divided personality cannot be moral at all.

While the really divided moral personality is exceptional, more common are internally differentiated moral personalities whose different moral 'selves' are only weakly interconnected. This means on the level of judgement that they are unable to justify the differences in their behaviour in various contexts. I am not sure whether their diverse moral concerns are weakly integrated with their identity. Their entire personality is weakly integrated. They lack unified agency. I guess that modern society fosters the prevalence of weakly unified moral personalities. In societies in which people participate in diverse social networks that are unrelated, they have a greater chance to get away with inconsistent behaviour. What is wrong with weakly unified moral personalities if their inconsistencies stay unnoticed? MacIntyre remarks that divided moral personalities (in my terminology differentiated moral personalities) who only strive for excellence in the performance of a particular role often suffer from a certain blindness to the values and obligations of other roles, even from fanaticism. I agree with him, but would deny that persons of moral integrity are by definition free from such blindness. Recall what I said about the plurality of diverse and sometimes conflicting, incommensurable values and virtues that cannot be united in one person. But persons of moral integrity will most certainly suffer less from the above mentioned blindness.

Persons who constantly hop from one role to another do not have a chance to grow in moral unity. Ethics has tried to answer moral questions arising in various social contexts by developing specialised sub-disciplines (such as business ethics, lawyers' ethics, nursing ethics, environmental ethics and so on). This specialisation might make some sense, but it does not further moral unification. An absolute condition for fostering moral unity is that there are places outside or in the interstices of specialised social roles and contexts where people are stimulated to search for and reflect upon the incoherencies and inconsistencies in their moral life. 


\section{MORAL EDUCATION IN SCHOOLS}

Much of what has been said above about education for moral integrity applies to the education that takes places within schools. Since it is, especially in modern societies, impossible to impose a social morality upon children, it is imperative that they learn to understand that no one can legislate a morality on its own and just for himself. This is even more necessary in a culture that highly values authenticity and loyalty to one's 'deepest self'. Moral education in schools is especially subject to the continuous tension between personal and moral integrity. Although morality cannot be the product of individual self-legislation, it is also not a treasure that just has to be discovered or a manual that has to be followed blindly. It needs to be the subject of much dialogue and debate, especially in multicultural communities. Such dialogue can start with everyday problems that children meet in their school life. They have for example to understand that the Moroccan girl in my example is not simply mad because she makes some sacrifices for the values she wants to preserve by remaining a member of her community. Children also need to learn that morality, although it demands sacrifices, need not be self-frustrating. Persons of moral integrity are not necessarily dull conformists who shield themselves from all temptations and pleasures that children regard as part of 'real life'. They need to be confronted with examples of real persons who live a life of moral integrity while enjoying the fullness of life. Reading biographies can help. ${ }^{11}$ And maybe they will be lucky enough to find such persons among their teachers.

Correspondence: Albert W. Musschenga, Institute for Ethics, Vrije Universiteit, De Boelelaan 1115, 1081 HV Amsterdam, The Netherlands. E-mail: aw.musschenga@mdw.vu.nl

\section{NOTES}

1. By internal inconsistency I mean logical contradiction between values and beliefs. Incoherence means that values and beliefs do not go together very well. Suppose that green cars are not allowed to exceed a speed of 50 miles per hour, while the limit for all other cars is 60 . Although there is no clear contradiction between these rules, any coherence is absent. If someone who holds the opinion that all economic refugees should be sent back when the police find them without the appropriate documents is not in favour of strict controls at borders and (air)ports, his convictions are incoherent.

2. In my paper 'Integrity - personal, moral and professional' (Musschenga, 2001) I provide the arguments for this assumption.

3. Cheshire Calhoun criticises views of integrity when they disregard the fact that integrity is a social trait. What makes it a social virtue is that it fits persons for community membership (1995, p. $257 \mathrm{ff}$.). In my view that is only a characteristic of material concepts of integrity, especially of moral integrity, and not of integrity as such.

4. One does not have to share Mackie's view of human motivations to recognise the need for such a distinction. Steven Lukes' argument - which I agree with - is that a system of rights and obligations is needed because of the existence of a plurality of sometimes conflicting moral principles, values and virtues. We need a narrow morality because individuals unavoidably come into conflict when each is pursuing his own conception of the good, even if they are not egoists (Lukes, 1991, p. 30 ff.). 
5. The assumption, present in theories of personality as well as in lay psychology, that individuals display a substantial degree of consistency in their behaviour has been heavily criticised in social psychology since the end of the 1960s. So-called situationist theories contend that people (1) are inclined to infer traits or dispositions from behaviour that is manifestly situationally produced, (2) tend to overlook situational factors of substantial importance, and (3) make overtly confident predictions when given a small amount of trait-relevant information. (For a good overview on situationism see Ross and Nisbett, 1991.) Some authors hold the opinion that consistency and inconsistency are not intrinsic properties of behaviour, but judgements by an observer about the match between behaviours and the observer's own category system (for example, Bem, 1984, p. 202 f., quoted by Flanagan, 1991 on p. 291). Situationists need not deny that individuals display some behavioural consistency. They interpret such consistency as stability of specific responses to specific situations. Flanagan's rejection of trait globality shows that he has learned from situationism. However, he does not follow situationists in their rejection of the concepts of traits. Gilbert Harman (1999) reproaches Flanagan on the grounds that he is not radical enough in taking social psychology's findings seriously. In my view, Flanagan knows the relevant literature better than Harman. Situationism is no longer as widely accepted as it was. It is now recognised that the debate between dispositionalism and situationism was about straw men (Kendrick and Funder, 1988; Tellegen, 1991). The current view is that trait concepts should delineate the particular circumstances under which the behavioural trait manifestations are likely to take place. This seems to be the position taken by Flanagan.

6. Flanagan gives a nice description of what narrative coherence consists in. He says that all of us have different selves - we display ourselves differently in contexts and roles. We are also constantly building an integrated self:

I draw my selves together, through the force of narrative gravity, and I comprehend my self in terms of a single, centered narrative in which they all fit together (but not without tension, various confusions, and much second-guessing). Taken together and consciously interwoven, they give my life what I take to be its unique qualitative character. (Flanagan, 1996, p. 71)

7. Flanagan does not exclude the possibility that there might be important probabilistic connections between traits and attitudes (1991, p. 289).

8. I found this phrase in Maria Merritt's 'Virtue ethics and situationist personality psychology' (Merritt, 2000). She discusses what consequences situationism has for conceptions of virtue ethics. In her view virtue ethics as such can accommodate the findings of situationist psychology. What becomes problematic is the normative ideal of the virtues as qualities that must be possessed in a strongly self-sufficient form, as is present, for example, in Aristotle's ethical theory. She defends a more Humean conception of virtue in which the importance of sustaining social contributions is recognised. Aristotle calls only those who have a motivationally self-sufficient character 'virtuous'. Normal virtuous persons will not be extremely motivationally self-sufficient. In Merritt's Humean view you do no have to be weak-willed to benefit from education for integrity.

9. A defence of the doctrine of the unity of the virtues is given by Bonnie Kent (1999).

10. This point has been raised by MacIntyre in his 'Social structures and their threat to moral agency' (MacIntyre, 1999). I discuss his views on moral fragmentation in my 'Integritypersonal, moral, and professional' (Musschenga, 2001).

11. I found some wonderful examples described by Anne Colby and William Damon in their Some Do Care (Colby and Damon, 1992). The 'moral exemplars' described by Anne Colby and William Damon are in my view persons of extraordinary moral integrity. All of them demonstrate the following characteristics: (1) a sustained commitment to moral ideals or principles that include a generalised respect for humanity or sustained evidence of moral virtue; (2) a disposition to act in accordance with one's moral ideals or principles, implying also a consistency between one's actions and intentions and between the means and ends of one's actions; (3) a willingness to risk one's self-interest for the sake of one's moral values; (4) a tendency to be inspiring to others and thereby to move them to moral action; and (5) a sense of realistic humility about one's own importance relative to the world at large, implying relative lack of concern for one's ego (Colby and Damon, 1992, p. 29). The first three characteristics converge with my volitional virtues and virtues of unified agency. Being inspiring to others may be a characteristic of extraordinary moral persons; it is not a requirement for being a person of 
moral integrity. Moreover, persons of moral integrity need not be altruists, but they will certainly not put their self-interest first.

\section{REFERENCES}

Blasi, A. (1995) Moral understanding and the moral personality: the process of moral integration, in: W.M. Kurtines and J.L. Gewirtz (eds) Moral Development: An Introduction (Boston, MA, Allyn \& Bacon), pp. 229-253.

Calhoun, C. (1995) Standing for something, Journal of Philosophy 92, pp. 235-261.

Colby, A. and Damon, W. (1992) Some Do Care: Contemporary Lives of Moral Commitment (New York, MA, MacMillan).

Flanagan, O. (1991) Varieties of Moral Personality (Cambridge, MA and London, Harvard University Press).

Flanagan, O. (1996) Self Expressions (New York and Oxford, Oxford University Press).

Gergen, K.J. and Gergen, M.M. (1983) Narratives of the self, in: T.R. Sarbin and K.E. Scheibe (eds) Studies in Social Identity (New York, Praeger), pp. 254-273.

Harman, G. (1999) Moral philosophy meets social psychology: virtue ethics and the fundamental attribution error, Proceedings of the Aristotelian Society 99, pp. 315-333.

Kamler, H. (2001) Self identity and moral maturity, in: A.W. Musschenga, A.W. Haaften, M. Slors and B. Spiecker (eds) Personal and Moral Identity (Dordrecht, Kluwer, forthcoming).

Kekes, J. (1983) Constancy and purity, Mind 92, pp. 499-518.

Kendrick, D.T. and Funder, D.C. (1988) Profiting from controversy: lessons from the personsituation debate, American Psychologist 49, pp. 23-34.

Kent, B. (1999) Moral growth and the unity of the virtues, in: D. Carr and J. Steutel (eds) Virtue Ethics and Moral Education (London and New York, Routledge), pp. 119-125.

Lukes, S. (1991) Taking morality seriously, in: Moral Conflict and Politics (Oxford, Clarendon Press), pp. 21-33.

MacIntyre, A. (1999) Social structures and their threats to moral agency, Journal of Philosophy 74, pp. 311-329.

Mackie, J.L. (1977) Ethics (Harmondsworth, Penguin).

Merritt, M. (2000) Virtue ethics and situationist personality psychology, Ethical Theory and Moral Practice 3, pp. 365-383.

Musschenga, A.W. (2001) Integrity — personal, moral and professional, in: A.W. Musschenga, A.W. van Haaften, M. Slors and B. Spiecker (eds) Personal and Moral Identity (Dordrecht, Kluwer, forthcoming).

Ross, L. and Nisbett, R.E. (1991) The Person and the Situation (New York, MA, McGraw-Hill).

Tellegen, A. (1991) Personality traits: issues of definition, evidence, and assessment, in: W.M. Grove and D. Cicchetti (eds) Thinking Clearly about Psychology. Volume 2: Personality and Psychopathology (Minneapolis and Oxford, University of Minnesota Press), pp. 10-35. 